\title{
Characterization of nanostructured ureteral stent with gradient degradation in a porcine model
}

\author{
This article was published in the following Dove Press journal: \\ International Journal of Nanomedicine \\ 20 April 2015 \\ Number of times this article has been viewed
}

\author{
Xiaoqing Wang' \\ Hongli Shan ${ }^{2}$ \\ Jixue Wang' \\ Yuchuan Hou' \\ Jianxun Ding ${ }^{3}$ \\ Qihui Chen' \\ Jingjing Guan' \\ Chunxi Wang \\ Xuesi Chen ${ }^{3}$ \\ 'Department of Urology, the \\ First Hospital of Jilin University, \\ ${ }^{2}$ Department of Clinical Laboratory, \\ the First Hospital of Jilin University, \\ ${ }^{3}$ Key Laboratory of Polymer \\ Ecomaterials, Changchun Institute \\ of Applied Chemistry, Chinese \\ Academy of Sciences, Changchun, \\ People's Republic of China
}

\begin{abstract}
A tubular poly(ع-caprolactone) (PCL)/poly(lactide-co-glycolide) (PLGA) ureteral stent composed of nanofibers with micropores was fabricated by double-needle electrospinning. The stent was ureteroscopically inserted into six Changbai pigs, and the commercial polyurethane Shagong ${ }^{\mathbb{B}}$ stent was inserted into four pigs as control. Intravenous pyelography revealed that the PCL/PLGA stent gradually degraded from the distal end to proximal terminal, and all stents were completely degraded at 10 weeks post-insertion. No significant difference was observed in hydronephrosis severity between the two groups. The levels of serum creatinine and urine $\mathrm{pH}$ remained similar throughout the study in the two groups, but the number of white blood cells in the urine was significantly higher in the Shagong ${ }^{\mathbb{R}}$ stent group. On Day 70, histological evaluation indicated equivalent histological severity scores in the middle and distal ureter sections and bladder in the two groups. However, the PCL/PLGA stent-implanted pigs had significantly lower mean severity scores in the kidney and proximal ureter sites. These data revealed that the PCL/PLGA stent degraded in a controlled manner, did not induce obstruction, and had a lower urothelial impact in comparison to the Shagong ${ }^{\mathbb{R}}$ stent, indicating that the stent exhibited great potential for clinical application.
\end{abstract}

Keywords: nanocomposites, polyesters, poly( $\varepsilon$-caprolactone), poly(lactide-co-glycolide), hydronephrosis severity

\section{Introduction}

The obstruction of urinary tract can occur during fetal development, childhood, or adulthood. The causes of obstruction may be congenital or postnatal, and may be benign or malignant. Some congenital diseases (eg, ureteropelvic junction obstruction and retrocaval ureter), secondary ureteral strictures, and trauma and iatrogenic injuries require reconstructive surgery. The application of a ureteral stent significantly increases the success rate of upper-urinary-tract reconstruction operations, maintains the drainage of urine, and prevents scar formation. However, some serious complications persist, including a separate cystoscopic procedure for removal, irritative voiding symptoms, hematuria, pain, infection, and encrustation. ${ }^{1-7}$

With the widespread application of degradable materials in medicine, the degradable ureteral stent can provide temporary urinary drainage, decrease morbidity, and preclude a secondary procedure for removal. The dissolvable stent produced by Lingeman et al showed the unsatisfactory results of poor fixation and a tendency to drop in clinical trials, which caused hydronephrosis and left debris in the pelvis. ${ }^{8}$ Chew et al invented several types of degradable Uriprene ${ }^{\mathrm{TM}}$ ureteral stents with undesirable results due to uncontrollable degradation, which involved the sudden disintegration of material and caused transient obstruction in animal trials. ${ }^{9-11}$ Fu and coworkers produced a polylactide (PLA) ureteral stent, and the animal trials validated that it required more than 80 days 
to achieve total degradation. ${ }^{12}$ In addition, some metal alloys have emerged as potential degradable biomaterials, but, as far as we are aware, no degradable metal ureteral stent has yet been reported in the literature. ${ }^{13,14}$

Our group has developed a variety of ureteral stents fabricated from poly(lactide-co-glycolide) (PLGA), with which we have made great progress to the current phase, but many urgent problems still remain: (1) the material is hard and brittle, exhibits poor shape memory, and lacks inner fixation; and (2) several fracture events occur during degradation, which cause ureteral obstruction. ${ }^{15,16}$

Electrospinning has gained much popularity recently as an enabling nanotechnology process for making seamless tubular scaffolds of various diameters and lengths from an assortment of synthetic and natural polymers for tissue engineering. ${ }^{17-19}$ The diameters of fibers and pore sizes of scaffolds can be controlled by the solution composition and spinning condition. ${ }^{20-23}$ In our previous study, the degradable poly( $\varepsilon$-caprolactone) (PCL)/PLGA stents with $5,10,15,20,25$, and $30 \mathrm{wt} \%$ of PCL were successfully fabricated by electrospinning. ${ }^{24,25}$ The stents have nanostructures with the pore sizes of $50-180 \mu \mathrm{m}$. It is supposed that urine can flow through the stent freely. The stent will not cause obstruction, even if broken. The obtained ureteral stents presented adjustable mechanical properties and in vitro degradability, and thus might meet the requirements of a degradable ureteral stent. ${ }^{24,25}$ Inspired by these results, a novel stent reported in this study containing gradient components of PCL and PLGA was designed and fabricated using the technique of double-nozzle electrospinning (Figure 1), in which PCL/PLGA solutions with 15 and $25 \mathrm{wt} \%$ of PCL were separately added to the two syringes. This stent comprised three parts: the proximal (25 wt $\%$ of PCL), middle (15 and $25 \mathrm{wt} \%$ of PCL), and distal (15 wt $\%$ of PCL). Because of the different contents of PCL, the stent would degrade gradually from the distal end to proximal terminal. In addition, the physiological and histological responses elicited by this stent were evaluated in a porcine model compared to those of standard biostable stents.

\section{Experimental section}

\section{Fabrication of ureteral stent}

PCL with a viscosity average molecular weight $\left(M_{\eta}\right)$ of 100,000 Da and PLGA (lactide (LA): glycolide (GA) =80:20) with $M_{\eta}$ of 60,000 Da were bestowed by Changchun SinoBiomaterials Co, Ltd (Changchun, People's Republic of China). PCL and PLGA were mixed at specific mass percentages; that is, the mixture contained 15 or $25 \mathrm{wt} \%$ of PCL. The mixtures were dissolved in chloroform at a concentration of $5 \mathrm{wt} \%$ to prepare a spinning solution. To achieve the X-ray-positive property, $10 \mathrm{wt} \%$ of barium sulfate was added to the solution. The apparatus for electrospinning comprised a high-voltage power supply $(0-50 \mathrm{kV})$, two $5.0 \mathrm{~mL}$ syringes containing a blunt $12 \mathrm{G}$ needle, and a rotating mandrel. The flow rate of the solution was controlled to $3.0 \mathrm{~mL} \mathrm{~h}^{-1}$, and the applied voltage, distance from the needle tip to mandrel, and the rotating rate were set to $20.0 \mathrm{kV}, 15.0 \mathrm{~cm}$, and $120.0 \mathrm{rpm}$, respectively. The scaffold was removed from the mandrel and dried.

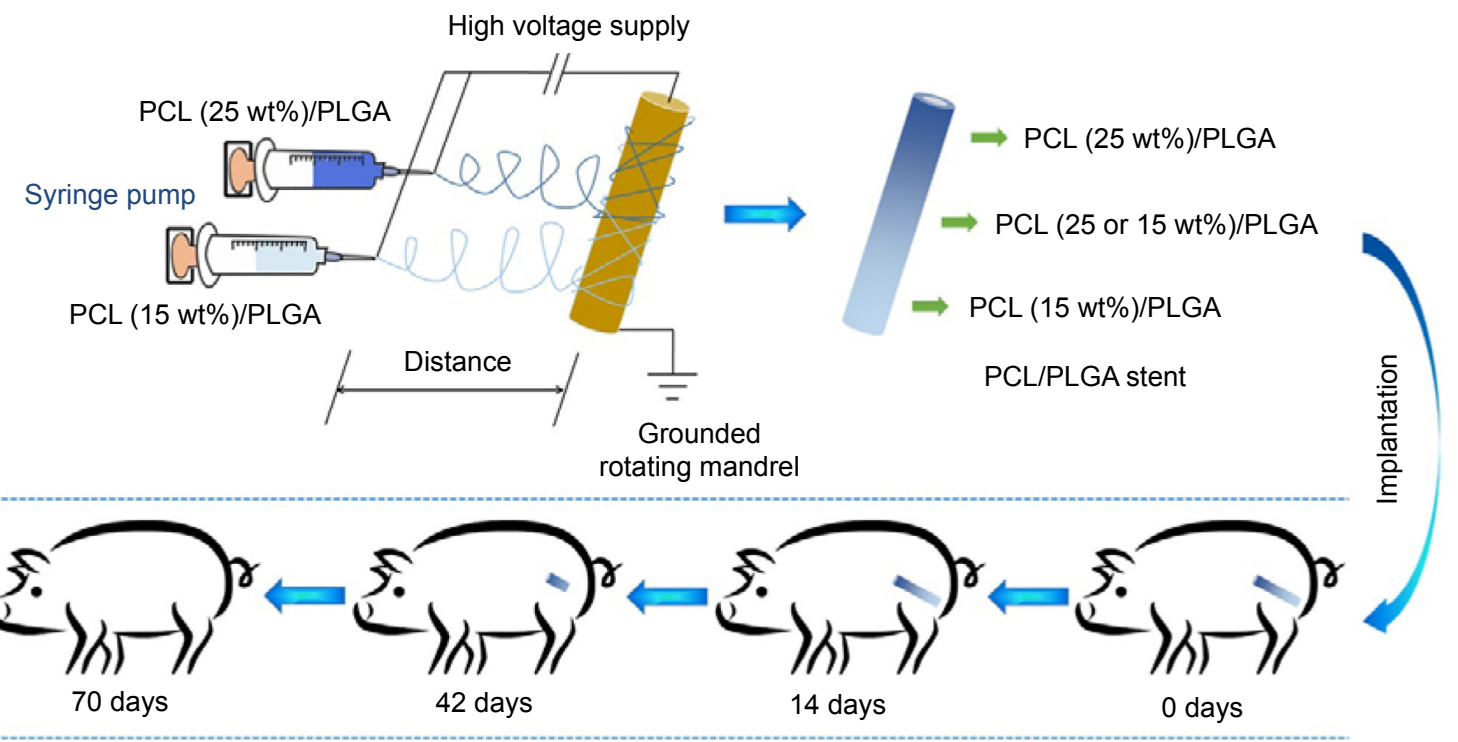

Figure I Schematic illustration of the fabrication of the poly( $\varepsilon$-caprolactone) (PCL)/poly(lactide-co-glycolide) (PLGA) stent and its gradient degradation after implantation into a porcine model. 
The microstructure of the stent was investigated by scanning electron microscopy (SEM). All test stents were previously sterilized before implantation by $\gamma$-irradiation.

\section{Animal procedure}

The study protocol was approved by the Institutional Animal Care and Use Committee of Jilin University, and all efforts were made to minimize suffering. A total of ten female Changbai pigs weighing 30-35 kg were used. The animals were ranked by weight and randomly divided into two groups. Six pigs were stented unilaterally and endoscopically with a biodegradable PCL/PLGA stent, and the remaining four pigs were stented with a $6 \mathrm{Fr}$ biostable polyurethane double "J" stent, which was cut into a single "J" stent with a length of $15 \mathrm{~cm}$ (Shagong ${ }^{\circledR}$, Zhangjiagang Shagong Medical Equipment Technology Development Co, Ltd, Jiangsu, People's Republic of China). Intravenous pyelography (IVP) was performed according to the schedule, that is, on Days 14, 28, 42, 56 and 70. Blood samples from the cephalic vein and urine samples were collected from all animals on Days $0,14,28,42,56$, and 70 . At 70 days, all animals were sacrificed, and necropsy was done.

\section{Stent insertion technique}

All the procedures were done under general anesthesia. All animals received intramuscular ceftazidime as antibiotic prophylaxis. Before stent insertion, urine was collected for urinalysis using an ureteroscope. A 0.035-inch-diameter polytetrafluoroethylene-coated Sensor ${ }^{\mathrm{TM}}$ Guidewire was inserted in the ureter, followed by an ureteroscope to confirm that there was no stricture or stone in the ureter. Then the ureteroscope was removed, and either a PCL/PLGA stent or commercial Shagong ${ }^{\circledR}$ stent was inserted over the guide wire. A Cook ${ }^{\circledR}$ pusher (Cook Medical Technologies LLC, Bloomington, IN, USA) was used to push the stent into the renal pelvis under fluoroscopic guidance. The guide wire was then removed, and only the stent was left. IVP was performed to confirm that the proximal end of the stent was in the renal pelvis, and the distal end was in the lower segment of the ureter.

\section{IVP}

In all animals, hydronephrosis was quantified by IVP on Days $0,14,28,42,56$, and 70, and the degree of hydronephrosis was categorized. At Level 0 , animals had an equivalent time for the passage of intravenous contrast agent in the stented kidney compared to in the contralateral non-stented kidney and an undilated collecting system; Level 1 was classified as a slightly prolonged time to see the contrast material in the kidney or mild dilatation of pelvis, calyx, or ureter; Level 2 was classified as a deferred time to see the contrast reagent in the kidney or moderate hydronephrosis; Level 3, or severe hydronephrosis, was assigned when no contrast material was seen to enter the stented kidney, or a severely hydronephrotic kidney was seen.

\section{Sacrifice and necropsy}

At 10 weeks, all animals were sacrificed, and necropsy was done to excise the kidneys, ureters, and bladder en bloc. Gross pathological findings of certain organs were assessed at necropsy. In addition to any grossly abnormal tissue, a representative section of each organ was stained with hematoxylin and eosin $(\mathrm{H} \& \mathrm{E})$. Tissues from the two groups were compared. A severity grade of 0 to 4 was assigned to the urinary-tract tissues according to the literature: ${ }^{11}$ (1) dilatation, that is, an increased renal tubule diameter mainly in the papillae and medulla without an effect on the tubular epithelium; (2) hypertrophy/hyperplasia, referring to increased size or hypertrophy of individual transitional epithelial cells and increased layers or hyperplasia of the mucosal transitional epithelium; (3) inflammation and lymphoplasmacytic (infiltrates variable numbers of lymphocytes, plasma cells, macrophages, and eosinophils, which occurred in the interstitium in multiple foci); and (4) vacuolation, cytoplasmic, and mucinous (distinct cytoplasmic vacuoles in transitional epithelium containing pale blue-gray, amorphous material characterized as mucus by a positive periodic acid-Schiff stain in select sections).

\section{Statistical analysis}

Results are expressed as mean \pm standard deviation. One-way analysis of variance (ANOVA) was used to compare the quantitative data between the PCL/PLGA stent and Shagong ${ }^{\circledR}$ stent groups. Hydronephrosis scores were compared using two-way repeated-measures ANOVA and Bonferroni's post hoc test. Statistical analysis was carried out using SPSS software (v 17.0; IBM Corporation, Armonk, NY, USA). A $P$-value of 0.05 was considered to be statistically significant.

\section{Results}

\section{Morphology of stent}

Figure 2A is a digital photo of a PCL/PLGA stent. The stent was white, with a length of $15-20 \mathrm{~cm}$, an inner diameter of $1.5 \mathrm{~mm}$, and an outer diameter of $2.0 \mathrm{~mm}$. There was no coil in each end of the stent. The stent was soft with some toughness and shape memory, and it could not be easily broken by bending. Figure 2B is an SEM microimage of the stent. The stent was composed of nanofibers with a multi-pore structure, and the diameters of the fibers were 120-1,100 nm and the pore sizes were $60-160 \mu \mathrm{m}$. 


\section{A}

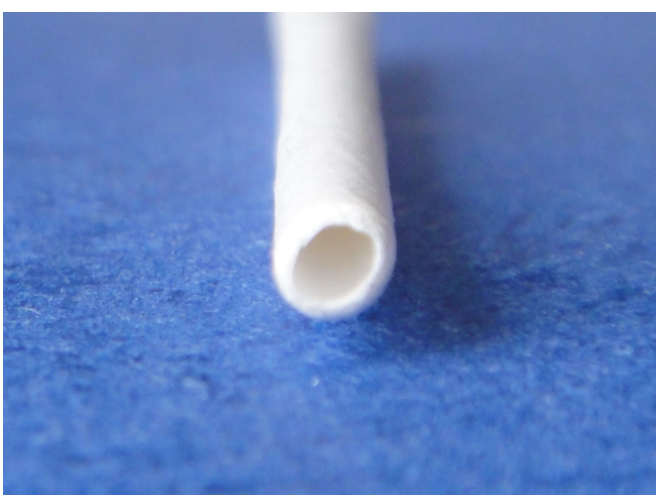

B

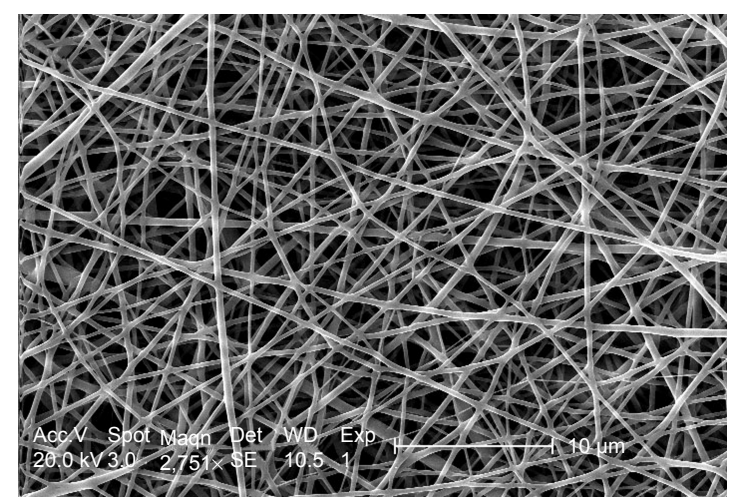

Figure 2 (A) Digital photo and (B) scanning electron microscopy image of the poly(E-caprolactone)/poly(lactide-co-glycolide) stent. Note: Scale bar in $\mathbf{B}=10 \mu \mathrm{m}$.

\section{Animal operations}

A total of ten pigs with a mean weight of $34.0 \pm 1.6 \mathrm{~kg}$ were successfully stented unilaterally using a biodegradable PCL/PLGA stent $(n=6)$ or a Shagong ${ }^{\circledR}$ stent $(n=4)$. There were no complications in the postoperative period. No stent migration or mortality occurred during the observation time. There were no difference in body weight in either group at any time points $(P>0.05)$ (Figure 3A). All pigs survived to the end of the study.

\section{Clinical biochemical analysis and urinalyses}

In the PCL/PLGA stent and Shagong ${ }^{\circledR}$ stent groups, the levels of creatinine in serum remained similar throughout the entire study.
A
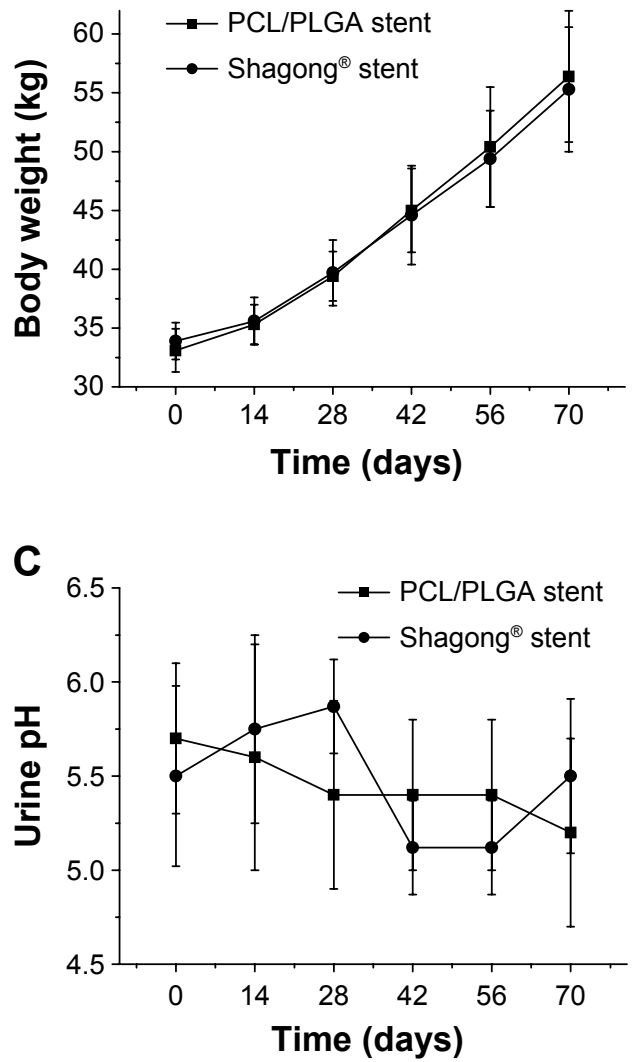

B

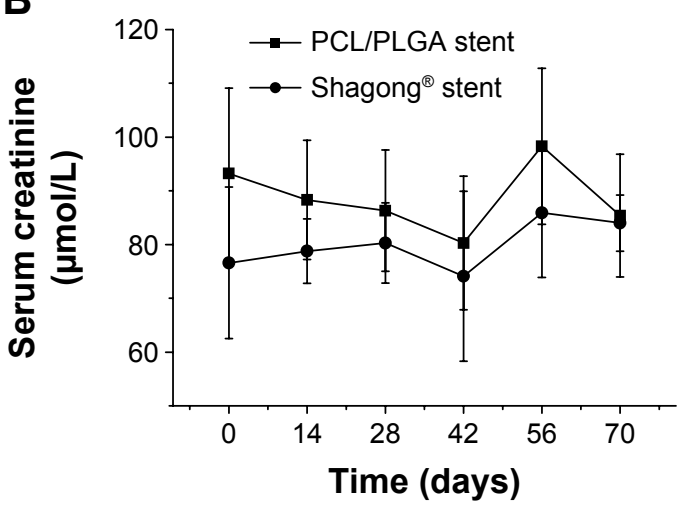

D

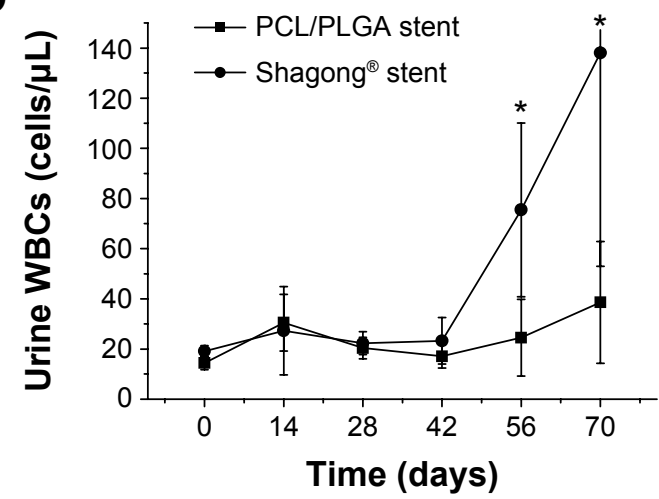

Figure 3 (A) Body weight, (B) serum creatinine, (C) urine $\mathrm{pH}$, and (D) urine white blood cells (WBCs) in the poly( $(\varepsilon$-caprolactone) (PCL)/poly(lactide-co-glycolide) (PLGA) stent- and Shagong ${ }^{\circledR}$ stent-implanted pigs as a function of time.

Notes: Data are presented as mean \pm standard deviation ( $n=6$ for the PCL/PLGA stent group and $n=4$ for the Shagong ${ }^{\circledR}$ stent [Zhangjiagang Shagong Medical Equipment Technology Development Co, Ltd, Jiangsu, People's Republic of China] group; * $P<0.05)$. 

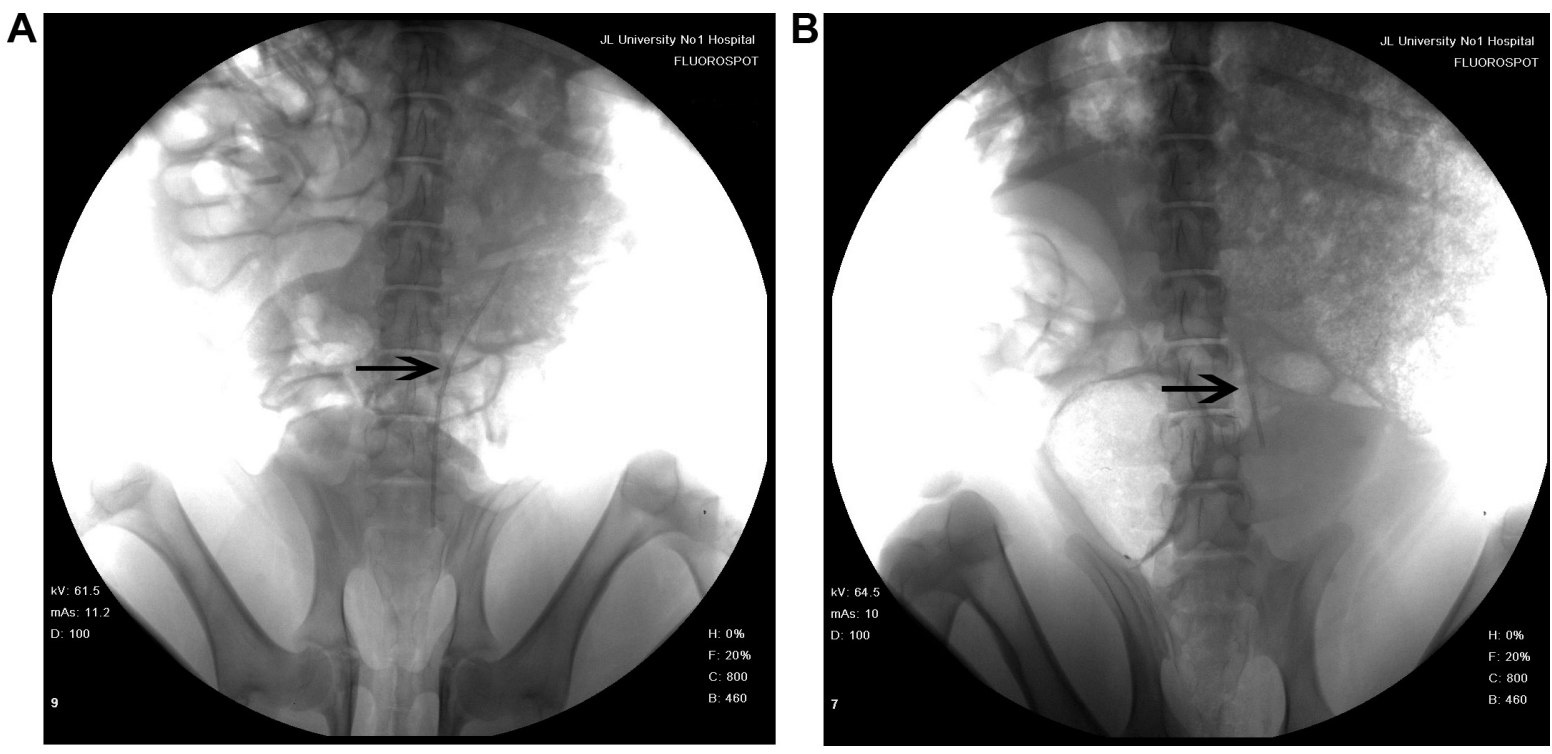

Figure 4 Representative abdominal X-ray films of the poly( $\varepsilon$-caprolactone) (PCL)/poly(lactide-co-glycolide) (PLGA) stent-implanted animals (A) at I4 days after insertion with no change in length, and (B) at 42 days with degradation of more than $50 \%$ in length. Arrow indicates PCL/PLGA stent.

That is, there was no difference in serum creatinine in either group at any time points $(P>0.05)$ (Figure $3 \mathrm{~B})$. In addition, urinalyses showed that there was also no difference in urine $\mathrm{pH}$ between the two groups ( $P>0.05)$ (Figure 3C), but the number of white blood cells (WBCs) in the Shagong ${ }^{\mathbb{B}}$ stent group was apparently higher after 8 weeks $(P<0.05)$ (Figure 3D).

\section{Degradation of PCL/PLGA stent in vivo}

Fourteen days after implantation, the PCL/PLGA stents showed no change in length (Figure 4A). All the implanted PCL/PLGA stents began to degrade in the distal end at 28 days, and four stents had degraded by more than $50 \%$ of their length at 42 days (Figure 4B). Four stents were completely degraded at around 56 days, and all stents were completely degraded before Day 70 . There was no incidence of ureteral obstruction due to the degraded stent fragments and no retained pieces in the kidneys of test animals.

\section{IVP results}

IVP was performed to assess hydronephrosis. In the PCL/PLGA stent group, hydronephrosis was observed after 14 days (Figure 5A), and hydronephrosis was decreased at 42 days (Figure 5B). Only one case of mild hydronephrosis remained at 70 days (Figure 5C). In the Shagong ${ }^{\circledR}$ stent group, a massively calcified stent caused a severe hydronephrosis (Figure 5D). On Day 42, no significant differences were observed in hydronephrosis severity score between the PCL/PLGA stent- and Shagong ${ }^{\circledR}$ stent-implanted pigs $(P>0.05)$. As the indwelling time increased beyond 56 days, the level of hydronephrosis increased significantly in the Shagong ${ }^{\circledR}$ stent group $(P<0.05)$ (Figure 6). Fortunately, it remained constant in the PCL/PLGA stent group.

\section{Pathological assessments}

On Day 70, all pigs underwent necropsy following an overdose of anesthesia. The sizes of stented kidneys in each group were similar to those of non-stented kidneys (Figure 7A). No stent pieces were observed in the renal pelvis, ureter, or bladder. In the Shagong ${ }^{\circledR}$ stent group, as previously mentioned, a massively calcified stent was observed (Figure 7B). On Day 70, the inflammation or hydronephrosis indicated by histopathological assays was more frequent and severe in the stented kidneys than in the non-stented kidneys. Interestingly, the bullous edema, an irregular surface and increased thickness of urothelium, was present only in the Shagong ${ }^{\circledR}$ stent group (Figure 7C-F). It appears that the PCL/PLGA stent produced less bladder irritation and inflammation. No difference in histopathological severity score was observed in the middle and distal ureter sections, or the bladders of the PCL/PLGA stent- and Shagong ${ }^{\circledR}$ stentgrafted animals $(P>0.05)$. In contrast, the PCL/PLGA stentimplanted pigs had significantly lower mean severity scores in the kidney and proximal ureter sections than the Shagong ${ }^{\circledR}$ stent-implanted control pigs $(P<0.05)$ (Figure 8$)$.

\section{Discussion}

The PCL/PLGA stent is designed to degrade from the distal end to proximal terminal due to the different proportions of the stent. 
A

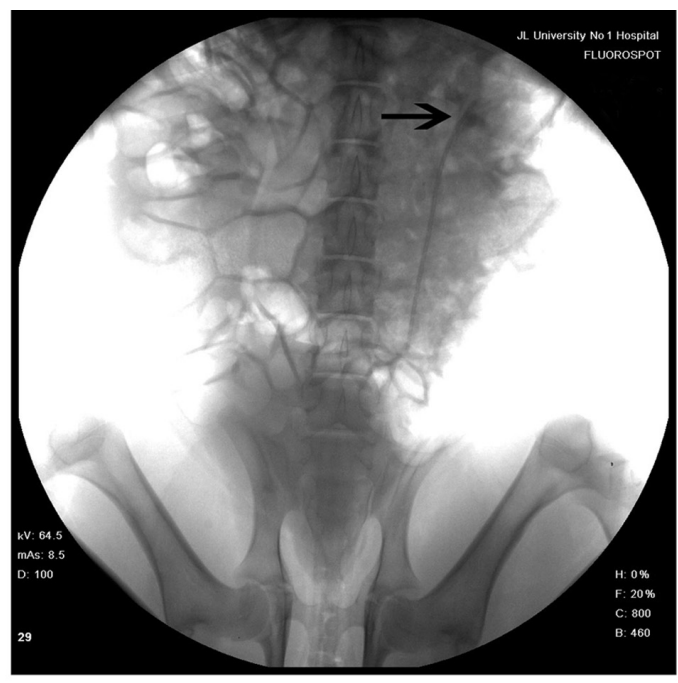

C

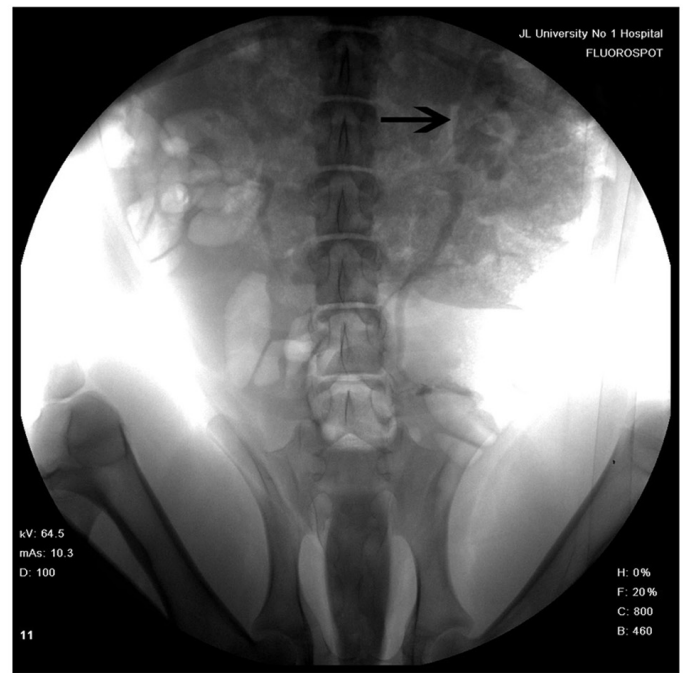

B

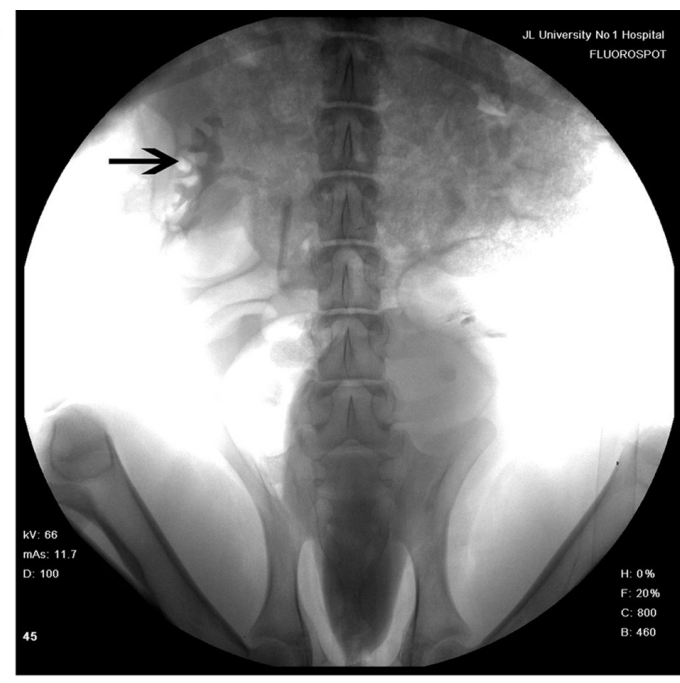

D

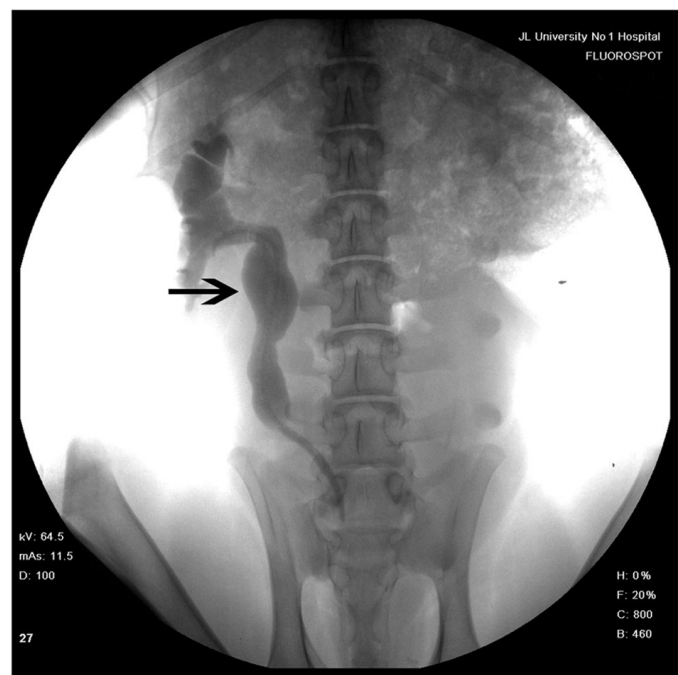

Figure 5 Intravenous pyelography images of the poly( $\left(\varepsilon\right.$-caprolactone) (PCL)/poly(lactide-co-glycolide) (PLGA) stent (A-C) and Shagong ${ }^{\circledR}$ stent (D): (A) a mild hydronephrosis image at I 4 days preoperatively; (B) the stent had degraded, and hydronephrosis was decreased at 42 days postoperatively; (C) in one case, mild hydronephrosis in the PCL/ PLGA stent remained at 70 days; (D) a massively calcified stent caused a severe hydronephrosis in the Shagong ${ }^{\circledR}$ stent group at 70 days.

Note: Arrows indicate renal pelvis or ureter. Shagong ${ }^{\circledR}$ stent (Zhangjiagang Shagong Medical Equipment Technology Development Co, Ltd, Jiangsu, People’s Republic of China).

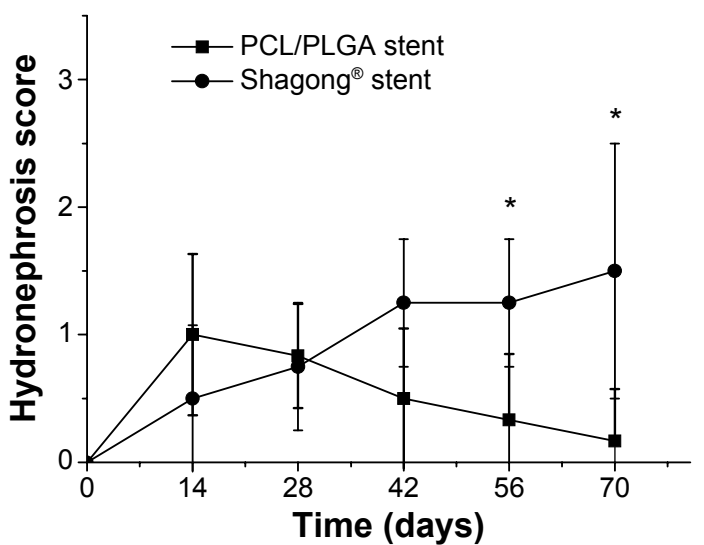

Figure 6 Intravenous pyelography hydronephrosis scores of the poly(E-caprolactone) (PCL)/poly(lactide-co-glycolide) (PLGA) stent- and Shagong ${ }^{\circledR}$ stent-implanted kidneys. Notes: Data are presented as mean \pm standard deviation ( $n=6$ for the PCL/PLGA stent group and $n=4$ for the Shagong ${ }^{\circledR}$ stent [Zhangjiagang Shagong Medical Equipment Technology Development Co, Ltd, Jiangsu, People's Republic of China] group; $* P<0.05$ ).
The degradation results show that the stents began to degrade at 4 weeks, and four stents had degraded by more than $50 \%$ in length at 6 weeks. Four stents had completely degraded by Week 8 , and all stents had completely degraded before Week 10. No fragment was observed during the whole observation time. The results mean that the stent can degrade gradually from the distal terminal to proximal end. This unique feature eliminates the potential for ureteral obstruction due to degrading stent fragments in the distal ureter that may lead to hydronephrosis and renal damage. ${ }^{11}$ More importantly, the degradation time of the PCL/PLGA stent with gradient degradation is consistent with the ureteral recovery time in clinical practice.

The degradation rate of PLGA is related to the $\mathrm{pH}$ value of the environment. In the media conditions with lower $\mathrm{pH}$, 
A

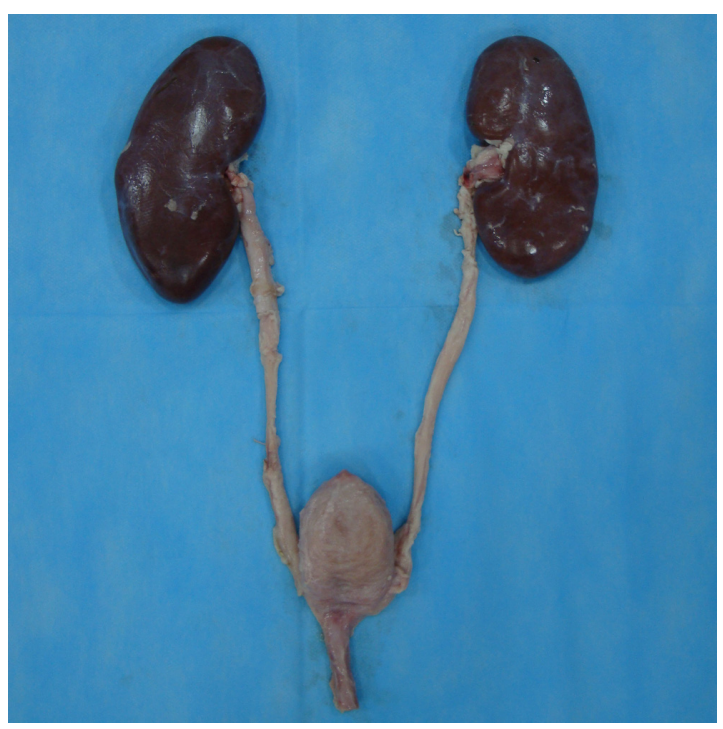

C

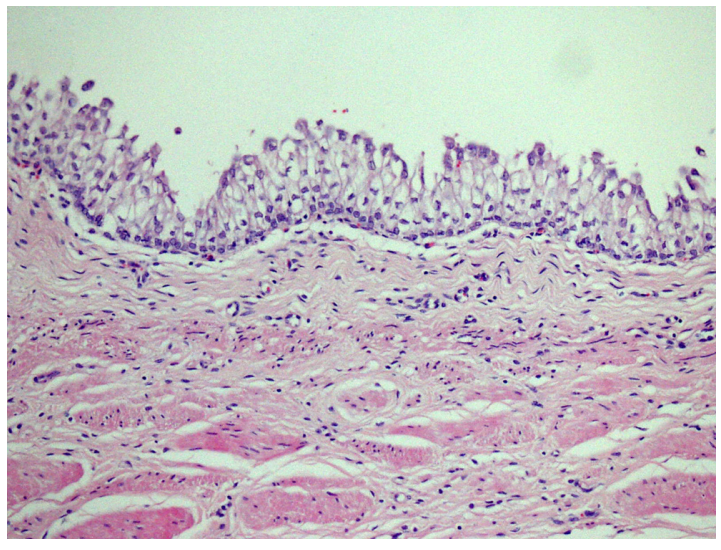

E

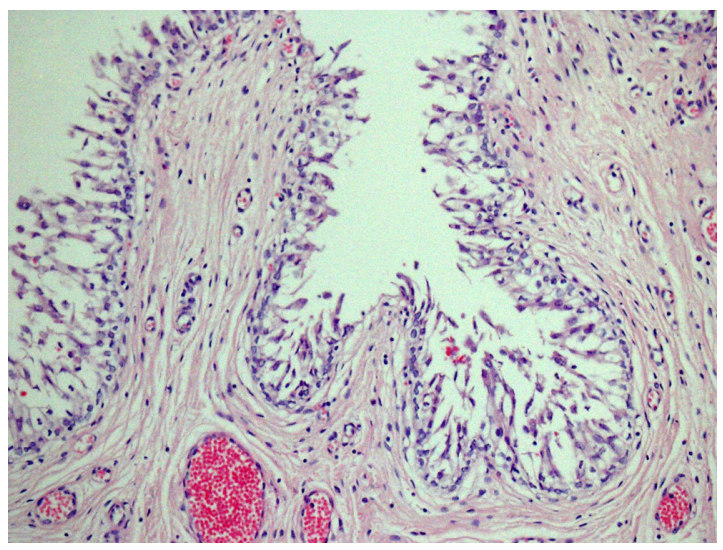

B

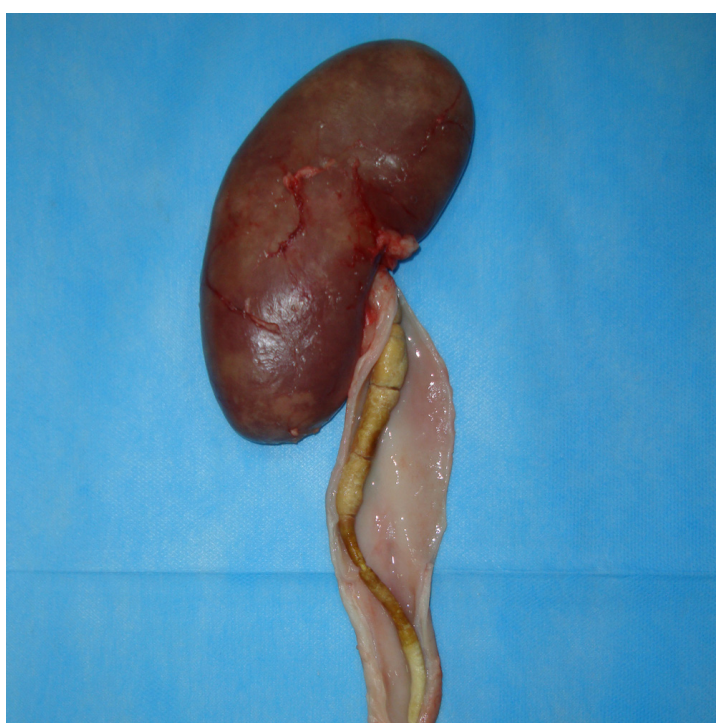

D

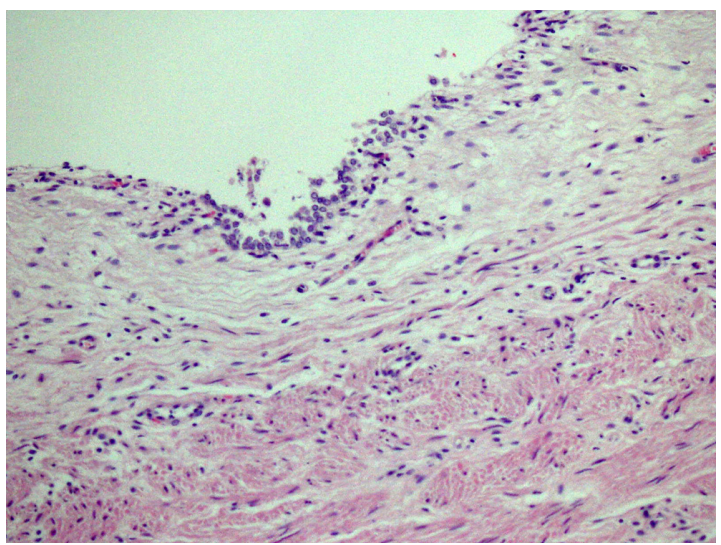

$F$

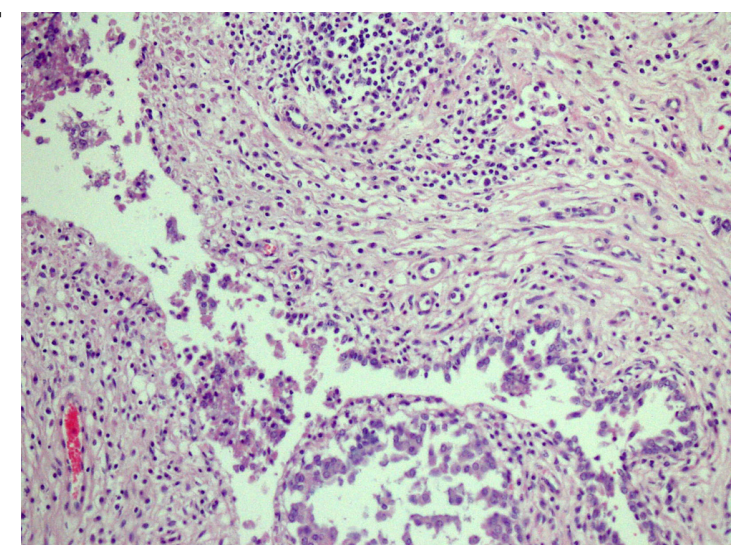

Figure 7 Representative macroscopic and microscopic images of the urinary tract: (A) the poly(E-caprolactone) (PCL)/poly(lactide-co-glycolide) (PLGA) stent-treated pig on Day 70 after insertion showing no dilatation of renal pelvis or ureter; (B) the Shagong ${ }^{\circledR}$ stent-grafted pig at 70 days after insertion showing a massively calcified stent and a dilated ureter; representative histopathological microimages of tissue slides revealing (C) normal epithelium (PCL/PLGA stent) and (D) inflammatory cell infiltration (Shagong ${ }^{\circledR}$ stent) of the renal pelvis; representative histopathological microimages showing (E) normal epithelium (PCL/PLGA stent) and (F) severe inflammation of the ureter (Shagong ${ }^{\circledR}$ stent) on Day 70.

Note: Magnification is $\times 200$ in $(\mathbf{C}-\mathbf{F})$.

PLGA degrades faster generally. ${ }^{26-29}$ Auge et al reports that the human urinary milieu is different from that of animals, whereas urinalyses indicate that the urine $\mathrm{pH}$ values of animals are close to those of humans. ${ }^{30}$ The degradation products of PLGA are acidic, and are easily metabolized in and eliminated from the body via the Krebs cycle. ${ }^{31}$ There were no differences in $\mathrm{pH}$ values between the two groups during the observation time $(P>0.05)$. This implies that the degradation of the stent does not change the $\mathrm{pH}$ of urine, and that it is safe for clinical use. 

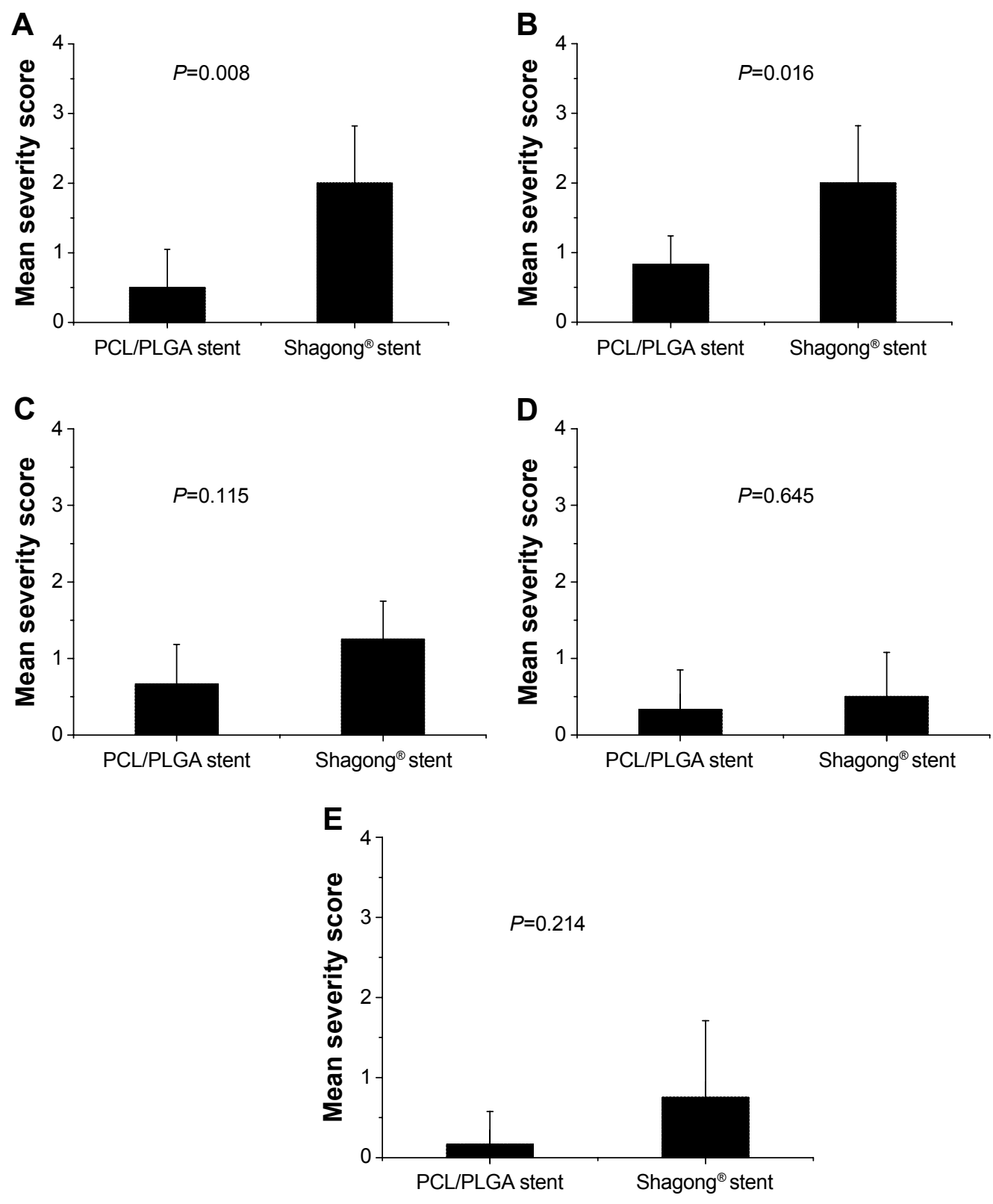

Figure 8 Mean histological severity scores in different urinary segments of animals in the poly( $\varepsilon$-caprolactone) (PCL)/poly(lactide-co-glycolide) (PLGA) stent and Shagong ${ }^{\circledR}$ stent groups for (A) the kidney, (B) proximal ureter, (C) middle ureter, (D) distal ureter, and (E) bladder.

Note: Data are presented as a mean \pm standard deviation ( $n=6$ for the PCL/PLGA stent group and $n=4$ for the Shagong ${ }^{\circledR}$ stent [Zhangjiagang Shagong Medical Equipment Technology Development Co, Ltd, Jiangsu, People's Republic of China] group).

The clinical rate of urinary-tract infection related to ureteral stents is reported to be from 15.2 to $23.0 \%$, and increases with the indwelling time of the stent. ${ }^{32-35}$ In this study, the WBCs in the urine were counted to evaluate the infection instead of doing urine cultures due to the difficulty of getting uncontaminated urine samples. The levels of WBCs in the Shagong ${ }^{\circledR}$ stent group were apparently higher than those in the PCL/PLGA stent group after 8 weeks $(P<0.05)$. This may indicate that the PCL/PLGA stent causes less infection. The theoretical reason is that the continually changing surface of the degradable stent creates an unfavorable environment for bacterial adhesion and colonization. ${ }^{9}$
A ureteral stent can maintain the drainage of urine to decrease the extensive hydronephrosis caused by obstructing disease. However, whether stent implantation can cause or aggravate hydronephrosis is not clear..$^{11,36,37}$ In this study, the stent was designed to degrade from the distal terminal to proximal end. This unique feature eliminates the potential for ureteral obstruction caused by degrading fragments of the stent. Nephrosis was observed in both groups after 2 weeks, while was decreased at 4 weeks in the PCL/PLGA stent group. Chew et al declare that the physiological and histological responses elicited by a degradable ureteral stent in a porcine 
model resemble closely those of humans. ${ }^{10}$ The placement of a ureteral stent can cause hydronephrosis, and this is a natural response to the indwelling stent, even in the absence of an obstruction disease.

Biocompatibility is an important characteristic for ureteral stents. Both PLGA and PCL have excellent biocompatibility and have been approved by the US Food and Drug Administration for using as biomaterials. ${ }^{38-45}$ Our previous study showed that the PCL/PLGA stents fabricated by electrospinning have a good biocompatibility. ${ }^{24}$ In this study, no difference in histopathological severity score was observed in the middle and distal ureter sections or bladder between the two groups. In contrast, the PCL/PLGA stent group had significantly lower mean severity scores in the renal pelvis and proximal ureter sections than the Shagong ${ }^{\circledR}$ stent group. In addition, bullous edema, an irregular surface and increased thickness of urothelium, was present only in the Shagong ${ }^{\circledR}$ stent group. The reason for this may be that the urothelial cells in the PCL/PLGA stent group first reacted in the same way as those in the biostable Shagong ${ }^{\circledR}$ stent group, but self-recovered after the degradation of the stent. The results suggest that the PCL/PLGA stent may trigger fewer stent-associated symptoms than the commercial Shagong ${ }^{\circledR}$ stent.

\section{Conclusion}

In the study reported here, a PCL/PLGA stent with gradient degradation was first fabricated by double-nozzle electrospinning. All of the stents had degraded from the distal terminal to proximal end by 10 weeks, with no ureteral obstruction in any animal. According to the IVP results, the PCL/PLGA stent did not increase nephrosis compared to the Shagong ${ }^{\circledR}$ control stent in the implanted animals. In addition, the PCL/PLGA stent was more biocompatible than the control stent, considering foreign-body reactions, and tissue inflammation and edema. These excellent properties of the PCL/PLGA stent indicate its great potential for the clinical application in maintaining urine drainage while decreasing ureteral obstruction.

\section{Acknowledgments}

This study was financially supported by the National Natural Science Foundation of China (numbers 50973043, 51303174 , 51233004, and 51390484), the Development and Reform Commission of Jilin Province (number JF-2012C006-5), and the Scientific Development Program of Jilin Province (number 20120159).

\section{Disclosure}

The authors report no conflicts of interest in this work.

\section{References}

1. Falahatkar S, Hemmati H, Gholamjani Moghaddam K. Intracaval migration: an uncommon complication of ureteral Double-J stent placement. J Endourol. 2012;26(2):119-121.

2. Bonkat G, Rieken M, Müller G, et al. Microbial colonization and ureteral stent-associated storage lower urinary tract symptoms: the forgotten piece of the puzzle? World J Urol. 2013;31(3):541-546.

3. Karagüzel E, Kutlu O, Kazaz IO, Gür M, Dil E, Ozgür GK. Knotted ureteral stent: a rare complication of ureteral stent usage. Urol Res. 2012;40(6):793-795.

4. Carrouget J, Ammi M, Lasocki S, et al. Double-J ureteral stent under local anesthesia for women. Can J Urol. 2014;21(1):7120-7124.

5. Kim JH, Park SY, Kim MG, et al. Pain and satisfaction during rigid cystoscopic ureteral stent removal: a preliminary study. BMC Urol. 2014; 14(1):90.

6. Zhou L, Cai X, Li H, Wang KJ. Effects of $\alpha$-Blockers, Antimuscarinics, or Combination Therapy in Relieving Ureteral Stent-Related Symptoms: A Meta-Analysis. J Endourol. 2014. Epub December 10.

7. Mercado A, Fernández MI, Recabal P, et al. Immediate postoperative morbidity in patients with indwelling double-J stent versus overnight-externalized ureteral catheter after tubeless percutaneous nephrolithotomy: a prospective, randomized study. Urolithiasis. 2013;41(3):253-256.

8. Lingeman JE, Preminger GM, Berger Y, et al. Use of a temporary ureteral drainage stent after uncomplicated ureteroscopy: results from a phase II clinical trial. J Urol. 2003;169(5):1682-1688.

9. Hadaschik BA, Paterson RF, Fazli L, Clinkscales KW, Shalaby SW, Chew BH. Investigation of a novel degradable ureteral stent in a porcine model. J Urol. 2008;180(3):1161-1166.

10. Chew BH, Lange D, Paterson RF, et al. Next generation biodegradable ureteral stent in a yucatan pig model. J Urol. 2010;183(2):765-771.

11. Chew BH, Paterson RF, Clinkscales KW, Levine BS, Shalaby SW, Lange $\mathrm{D}$. In vivo evaluation of the third generation biodegradable stent: a novel approach to avoiding the forgotten stent syndrome. $J$ Urol. 2013;189(2):719-725.

12. Li G, Wang ZX, Fu WJ, et al. Introduction to biodegradable polylactic acid ureteral stent application for treatment of ureteral war injury. $B J U$ Int. 2011;108(6):901-906.

13. Fan J, Qiu X, Niu X, et al. Microstructure, mechanical properties, in vitro degradation and cytotoxicity evaluations of Mg-1.5Y-1.2Zn$0.44 \mathrm{Zr}$ alloys for biodegradable metallic implants. Mater Sci Eng C Mater Biol Appl. 2013;33(4):2345-2352.

14. Hermawan H, Dubé D, Mantovani D. Degradable metallic biomaterials: design and development of Fe-Mn alloys for stents. J Biomed Mater Res A. 2010;93(1):1-11.

15. Wang CX, Hou YC, Wang Y, et al. [Evaluation of a new choanoid biodegradable ureteral stent in a canine model.] Chinese Journal of Urology. 2006;27(11):738-741. Chinese.

16. Hou YC, Wang CX, Chen XS, Zhang BG. Biocompatibility of a new ureteral stent made of biodegradable material. Chin J Exp Surg. 2006; 23(5):571-572.

17. Yin A, Zhang K, McClure MJ, et al. Electrospinning collagen/chitosan/

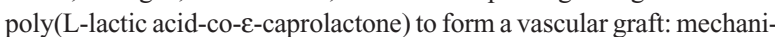
cal and biological characterization. J Biomed Mater Res A. 2013; 101(5):1292-1301.

18. Chae T, Yang H, Ko F, Troczynski T. Bio-inspired dicalcium phosphate anhydrate/poly(lactic acid) nanocomposite fibrous scaffolds for hard tissue regeneration: in situ synthesis and electrospinning. $J$ Biomed Mater Res A. 2014;102(2):514-522.

19. Seil JT, Webster TJ. Spray deposition of live cells throughout the electrospinning process produces nanofibrous three-dimensional tissue scaffolds. Int J Nanomedicine. 2011;6:1095-1099.

20. Hemp ST, Hudson AG, Allen MH Jr, Pole SS, Moore RB, Long TE. Solution properties and electrospinning of phosphonium gemini surfactants. Soft Matter. 2014;10(22):3970-3977.

21. Woods I, Flanagan TC. Electrospinning of biomimetic scaffolds for tissue-engineered vascular grafts: threading the path. Expert Rev Cardiovasc Ther. 2014;12(7):815-832. 
22. Chen H, Fan X, Xia J, et al. Electrospun chitosan-graft-poly ( $\varepsilon$-caprolactone)/poly( $\varepsilon$-caprolactone) nanofibrous scaffolds for retinal tissue engineering. Int J Nanomedicine. 2011;6:453-461.

23. Zhang J, He L, Xu H, et al. Molecular weight-modulated electrospun poly( $\varepsilon$-caprolactone) membranes for postoperative adhesion prevention. RSC Adv. 2014;2014(4):41696-41704.

24. Wang X, Chen QH, Hou YC, Jiang FM, Wang Y, Wang CX. The biocompatibility of polycaprolactone/poly(lactic acid - glycolic acid) degradable nano-structure ureteral stent fabricated by electrospinning. Chin J Exp Surg. 2012;29(5):864.

25. Wang X, Hou Y, Chen Q, Jiang F, Wang Y, Wang C. [Preparation of polycaprolactone/poly(lactic acid-glycolic acid) biodegradable nanostructure ureteral stent and its degradation assay in vitro.] Chinese Journal of Urology. 2014;35(4):293-296. Chinese.

26. Hild N, Tawakoli PN, Halter JG, et al. pH-dependent antibacterial effects on oral microorganisms through pure PLGA implants and composites with nanosized bioactive glass. Acta Biomater. 2013;9(11): 9118-9125.

27. Liu Y, Schwendeman SP. Mapping microclimate $\mathrm{pH}$ distribution inside protein-encapsulated PLGA microspheres using confocal laser scanning microscopy. Mol Pharm. 2012;9(5):1342-1350.

28. Schädlich A, Kempe S, Mäder K. Non-invasive in vivo characterization of microclimate $\mathrm{pH}$ inside in situ forming PLGA implants using multispectral fluorescence imaging. J Control Release. 2014;179:52-62.

29. Ding AG, Schwendeman SP. Acidic microclimate $\mathrm{pH}$ distribution in PLGA microspheres monitored by confocal laser scanning microscopy. Pharm Res. 2008;25(9):2041-2052.

30. Auge BK, Ferraro RF, Madenjian AR, Preminger GM. Evaluation of a dissolvable ureteral drainage stent in a Swine model. J Urol. 2002; 168(2):808-812.

31. Lü JM, Wang X, Marin-Muller C, et al. Current advances in research and clinical applications of PLGA-based nanotechnology. Expert Rev Mol Diagn. 2009;9(4):325-341.

32. Klis R, Korczak-Kozakiewicz E, Denys A, Sosnowski M, Rozanski W. Relationship between urinary tract infection and self-retaining Double-J catheter colonization. J Endourol. 2009;23(6):1015-1019.

33. Joshi R, Singh DR, Sharma S. Lower urinary tract infection and bacterial colonization in patient with double Jureteral stent. JNepal Health Res Counc. 2011;9(2):165-168.

34. Makadia HK, Siegel SJ. Poly Lactic-co-Glycolic Acid (PLGA) as Biodegradable Controlled Drug Delivery Carrier. Polymers (Basel). 2011; 3(3):1377-1397.
35. Bonkat G, Braissant O, Rieken M, et al. Comparison of the roll-plate and sonication techniques in the diagnosis of microbial ureteral stent colonisation: results of the first prospective randomised study. World J Urol. 2013;31(3):579-584.

36. Dallwig RK, Langan JN, Hatch DA, Terio KA, Demitros C. Bilateral hydronephrosis secondary to endometriosis managed by endoscopic ureteral stent placement in a captive Guinea baboon (Papio papio). J Zoo Wildl Med. 2011;42(4):747-750.

37. Sakamoto H, Matsuda A, Kanno T, Yamada H. [Retrospective analysis of the long-term indwelling ureteral stent.] Hinyokika Kiyo. 2012; 58(6):269-272. Japanese.

38. Vysloužil J, Doležel P, Kejdušová M, Košt'ál V, Beneš L, Dvořáčková K. Long-term controlled release of PLGA microparticles containing antidepressant mirtazapine. Pharm Dev Technol. 2014. Epub December 11.

39. Paskiabi FA, Mirzaei E, Amani A, Shokrgozar MA, Saber R, Faridi-Majidi R. Optimizing parameters on alignment of PCL/PGA nanofibrous scaffold: An artificial neural networks approach. Int J Biol Macromol. 2014. Epub October 27.

40. Ferrand A, Eap S, Richert L, et al. Osteogenetic properties of electrospun nanofibrous PCL scaffolds equipped with chitosan-based nanoreservoirs of growth factors. Macromol Biosci. 2014;14(1):45-55.

41. Chen Y, Wang J, Shen B, et al. Engineering a Freestanding Biomimetic Cardiac Patch Using Biodegradable Poly(lactic-co-glycolic acid) (PLGA) and Human Embryonic Stem Cell-derived Ventricular Cardiomyocytes (hESC-VCMs). Macromol Biosci. 2014. Epub November 25.

42. Reinhold SE, Schwendeman SP. Effect of polymer porosity on aqueous self-healing encapsulation of proteins in PLGA microspheres. Macromol Biosci. 2013;13(12):1700-1710.

43. Chang PC, Chung MC, Lei C, Chong LY, Wang CH. Biocompatibility of PDGF-simvastatin double-walled PLGA (PDLLA) microspheres for dentoalveolar regeneration: a preliminary study. J Biomed Mater Res A. 2012;100(11):2970-2978.

44. Du BL, Zeng CG, Zhang W, Quan DP, Ling EA, Zeng YS. A comparative study of gelatin sponge scaffolds and PLGA scaffolds transplanted to completely transected spinal cord of rat. J Biomed Mater Res A. 2014; 102(6):1715-1725.

45. Shin YC, Yang WJ, Lee JH, et al. PLGA nanofiber membranes loaded with epigallocatechin-3-O-gallate are beneficial to prevention of postsurgical adhesions. Int J Nanomedicine. 2014;9:4067-4078.
International Journal of Nanomedicine

\section{Publish your work in this journal}

The International Journal of Nanomedicine is an international, peerreviewed journal focusing on the application of nanotechnology in diagnostics, therapeutics, and drug delivery systems throughout the biomedical field. This journal is indexed on PubMed Central, MedLine, CAS, SciSearch ${ }^{\circledR}$, Current Contents ${ }^{\circledR} /$ Clinical Medicine,

\section{Dovepress}

Journal Citation Reports/Science Edition, EMBase, Scopus and the Elsevier Bibliographic databases. The manuscript management system is completely online and includes a very quick and fair peer-review system, which is all easy to use. Visit http://www.dovepress.com/ testimonials.php to read real quotes from published authors. 